of observation on the part of Gregory with the inference on the part of Suess, which could not but be convincing. The grandeur of the concepts appealed to Gregory's poetic thought, and he became for life an advocate of Suess's ideas of the development of the Indian Ocean basin by the foundering of Gondwanaland.

It is well known that weighty arguments in support of the general theory of lost continents may be adduced from palæontology, from the geological histories of Africa, Asia, and the Americas, as also from climatic changes throughout geological time. Gregory was master of them all. The scope of his knowledge was all-embracing. An eager student, a bold investigator, a rapid thinker, endowed with a capacious memory for facts and constructive capacity for synthesis, he became, as the result of his far-flung explorations, an outstanding authority on the world as a whole.

Gregory was, however, far from being a dogmatic theorist. Though tenacious and formidable in argument, he recognised the incompleteness of geological evidence and appreciated the obligation to consider advances in knowledge. In 1915 he wrote in "Geology of "To-day" :

"In order to free geology from hopeless attempts to solve problems which could not be solved with the knowledge then available, and to get rid of the incubus of unscientific and premature hypotheses, a group of English geologists founded the Geological Society of London.'

To that purpose he was loyal. In the words of Lyell, he conceived the ideal of the founders to have been "to multiply and record observations", and to that end he dared every risk and devoted his life unsparingly.

Gregory passed, as he would have wished, in active service. He leaves a most eminent name in the roster of great British geologists, but it cannot fill the emptiness in the hearts of his friends.

Stanford University,

BAILEY WIILIS. California.

\section{Appearance of a Rusty-Red Pigmentation in the Goats of Albino Rats in the Tropics}

Some details of the appearance of a reddish pigmentation in the coats of certain rats after importation into Trinidad from London may be of interest to geneticists.

The colony lies between ten and eleven degrees north of the equator. The shade temperature during the day ranges from $85^{\circ}$ to $95^{\circ}$. The night tempera ture is somewhat lower, especially in the dry season from December to March or April, when the lowest temperature is about $70^{\circ}$. The health of the rats was good. They arrived at the laboratory in November and December 1928. Forty-five were pink-eyed albinos, seven males and thirty-eight females; four were black-and-white, two males and two females, with the Dutch-rabbit distribution of pigment : these were all black-eyed. They were placed in roomy cages, four females to each male. No attempt was made to isolate the albinos from the black-and-white in the matings, as genetic experiments were no part of my programme. No alien blood of any kind was introduced. The only selection made was that animals varying in weight more than ten per cent above or below the average of their litter mates were discarded as unsuited for dietetic experiments.

The following notes were recorded :

January 1929 ; the albino offspring $(F 1)$ of the im. ported animals were of a creamy-yellow tint.

April 1929; second generation (F2) born. Some of the ratlings were reddish-yellow.

No. 3278, VoL. 130]
September 1929 ; the yellow colour became so marked in many of the rats that a profound change in metabolism seemed to have occurred. Paler yellows persisted, and some of the others with pink eyes showed the Dutch marking in pale yellow on a white ground. Black-and-whites still appeared, though in a decreased proportion.

December 1929 ; some of the rats were now of a rusty-red tint, like an English hare.

August and September 1931; the figures for the coloration of the animals employed during these two months were :

All rusty-red, of various shades, or all yellow

Rusty-red-(or yellow)-and-white

Black-and-white (Dutch-marked) $56\}=72$

Black with white belly .

4

$$
\text { Total . . . } 80 \text { rats. }
$$

A reddish strain of fancy rats similar to those described above and, like them, possessing pink eyes, is known to animal fanciers. These originated in Japan, coming, it is said, from Nagasaki, a place with a rather hot climate.

In May 1932, Dr. Wise, Surgeon-General of Trinidad, sent me some of the Trinidad red rats, descendants of those I had left there. These seem darker than those I saw last September. The eyes remain pink, and their bellies, though reddish, are lighter than the rest of the body. Four of this contingent are in a tropical house at Kew for breeding experiments.

On March 3, 1932, a male and two female albino Wistar rats from the Medical Research Council were sent to the same house to ascertain whether results similar to those found in Trinidad would be obtained. The conditions as to temperature and humidity are almost identical with those of Trinidad, the chief difference being the lesser amount of sunlight.

In a few weeks these rats showed a slight creaminess of tint, which was especially marked on the back of the neck.

Litters $(F 1)$ were born in March. These were all cream-coloured, in varying degrees of intensity. One male and two females of these were retained at Kew for breeding, the remainder being taken to the animal house at the London School of Hygiene and Tropical Medicine. In June, litters ( $F 2)$ were born, these being distinctly darker than their parents. The Kew-bred rats grew darker in colour both when retained in the tropical house and when brought to the School, but this latter result may be partly due to the fact that the end of June and the beginning of July were hot.

In addition to these facts, and possibly standing in some causal relationship with them, is the occurrence of extensive gastro-intestinal hæmorrhage in rats living in Trinidad or in a tropical house at Kew, when given for a few days a diet of water only. A few animals on this diet in the temperate climate showed traces of bleeding, but not more than traces, whereas in the tropical climate the appearance of the intestines resembles red-currant jelly.

\section{London School of Hygiene and \\ Alfred Clark.} Tropical Medicine,

Keppel Street, London, W.C.1, Aug. 2.

\section{Cytoplasmic Inclusions of Opalina and Nyctotherus}

A very interesting paper has recently appeared by Richardson and Horning, ${ }^{1}$ on the cytoplasmic structure of Protopalina and Nyctotherus cordiformis. In the opalinids these authors distinguish three classes of inclusions: first, darkly staining rod-like structures, the mitochondria, often in close connexion with the 